\section{Low Incidence of Neurologic Complications during Thoracic Epidurals: Anatomic Explanation}

Central neuraxial block has a low incidence of major complications, many of which resolve within 6 months. ${ }^{1}$ During attempts to insert a spinal needle into the lumbar subarachnoid space, patients occasionally experience paresthesia, with a reported incidence of $13.6 \% .{ }^{1} \mathrm{Neu}-$ rologic complications, including spinal cord injury, ${ }^{2}$ may arise during administration of the epidural block because the needle or catheter may cause direct nerve trauma. Accidental dural puncture during needle insertion occurred in $0.4 \%-1.2 \%$ of instances in a series of 6496 thoracic epidural blocks, but none of the 48 patients developed subsequent neurologic sequelae. ${ }^{3-5}$

Recently, the anatomy of the thoracic spinal canal was investigated with MR imaging in 50 patients. ${ }^{6}$ The space between the dura mater and spinal cord in the thoracic region measured with MR imaging was $5.19 \mathrm{~mm}$ at T2, $7.75 \mathrm{~mm}$ at T5, and $5.88 \mathrm{~mm}$ at T10 (Fig 1). The angle of entry between $\mathrm{T} 5$ and $\mathrm{T} 6$ ( $\mathrm{almost} 50^{\circ}$ ) elongated the distance from the tip of the needle to the posterior surface of the cord. MR imaging (Fig 1) confirms that the cord and the cauda equina are touching the dura mater posteriorly in the lumbar region and anteriorly in the thoracic region (the spinal cord). This position increases the distance to a point that permits the advancement of a needle without touching the cord, such as in the case of accidental perforation of the dura mater during the administration of spinal anesthesia. This can be an explanation for the low incidence of neurologic complications during accidental perforation of the dura mater in an attempt to perform a thoracic epidural block ${ }^{3-5}$ and the safety of segmental spinal anesthesia when using a thoracic approach. ${ }^{7,8}$

\section{References}

1. Pong RP, Gmelch BS, Bernards CM. Does a paresthesia during spinal needle insertion indicate intrathecal needle placement? Reg Anesth Pain Med 2009;34: 29-32

2. Gibson P. Spinal cord damage following thoracic epidural anaesthesia. Anaesth Intensive Care 2004;32:596-97, author reply 597

3. Scherer R, Schmutzler M, Giebler R, et al Complications related to thoracic epidural analgesia: a prospective study in 1071 surgical patients. Acta Anaesthesiol Scand 1993;37:370-74

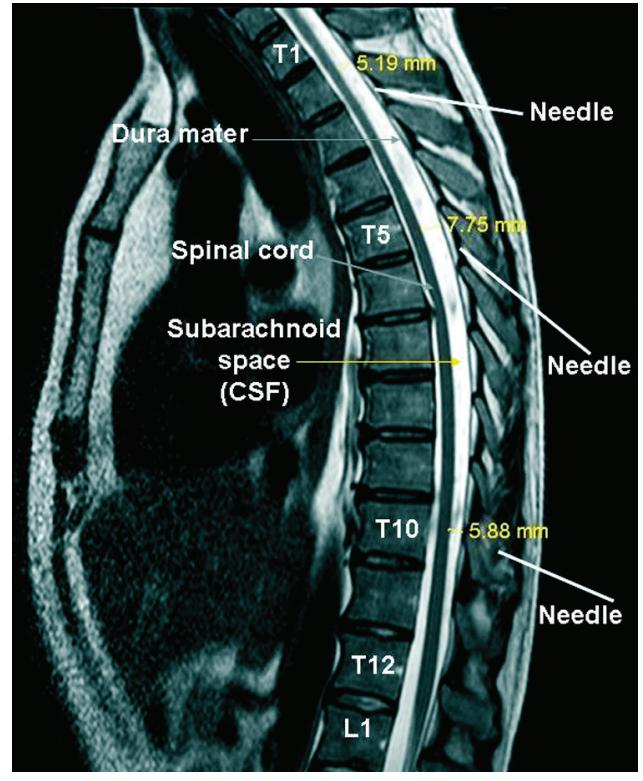

Fig 1. MR imaging of the thoracic column.

4. Giebler RM, Scherer RU, Peters J. Incidence of neurologic complications related to thoracic epidural catheterization. Anesthesiology 1997;86:55-63

5. Leão DG. Thoracic epidural anesthesia: analysis of 1240 cases. Rev Bras Anestesiol 1997;47:138-47

6. Imbelloni LE, Quirici MB, Ferraz-Filho JR, et al. The anatomy of the thoracic spinal canal investigated with magnetic resonance imaging. Anesth Analg 2010;110:1494-95

7. van Zundert AA, Stultiens G, Jakimowicz JJ, et al. Laparoscopic cholecystectomy under segmental thoracic spinal anaesthesia: a feasibility study. $\mathrm{Br} \mathrm{J}$ Anaesth 2007;98:682-86. Epub 2007 Mar 19

8. Imbelloni LE, Fornasari M, Fialho JC. Combined spinal epidural anesthesia during colon surgery in a high-risk patient: case report. Rev Bras Anestesiol 2009;59:741-45

L.E. Imbelloni

M.A. Gouveia

Instituto de Anestesia Regional Hospital de Base-FUNFARME São José do Rio Preto, SP, Brazil

DOI 10.3174/ajnr.A2227 